\title{
Fuzzy Logic Algorithms to Identify Birds, Precipitation, and Ground Clutter in S-Band Radar Data Using Polarimetric and Nonpolarimetric Variables
}

\author{
BASIVI RADHAKRISHNA \\ National Atmospheric Research Laboratory, Department of Space, Gadanki, India \\ FRÉDÉRIC FABRY AND ALAMELU KILAMBI \\ J. S. Marshall Radar Observatory, Department of Atmospheric and Oceanic Sciences, McGill University, Montreal, Quebec, Canada
}

(Manuscript received 24 May 2019, in final form 27 August 2019)

\begin{abstract}
The statistical properties of the radar echoes from biological, precipitation, and ground targets observed with the McGill S-band dual-polarization radar have been used to devise a polarimetric and a nonpolarimetric fuzzy logic algorithm for pixel-by-pixel target identification. Radar observations of migrating birds show distinctly different polarimetric features during their relative approach and departure from the radar site illustrating the dependency of radar parameters on the canting angle and scattering cross section. The devised algorithms have been tested with two independent events, each consisting of $2 \mathrm{~h}$ of radar observations with a 5-min temporal resolution. One event consisted of precipitation without birds while the other contained only birds. The misclassifications were $10.12 \%$ and $9.6 \%$, respectively, for the two cases for the nonpolarimetric algorithm, and $1.99 \%$ and $0.92 \%$ for the polarimetric algorithm. The results indicate that even though nonpolarimetric radar membership functions may be considered adequate for separating radar echo returns from birds, precipitation, and ground targets, they are not sufficiently skilled if a greater accuracy is required. Target identification without polarimetric variables especially fails in the region of zero isodop and in precipitation with an echo top below $4 \mathrm{~km}$.
\end{abstract}

\section{Introduction}

Weather radar data quality depends on the accurate identification of targets that cause a return to the radar. The great diversity seen in the radar observed and derived echo properties for meteorological and nonmeteorological targets allow us to devise various techniques to detect ground targets, precipitation particles and bird echoes in the radar returns using polarimetric and nonpolarimetric variables (Zrnić and Ryzhkov 1998; Steiner and Smith 2002; Liu et al. 2005; Bachmann and Zrnić 2007; Dokter et al. 2011; Kilambi et al. 2018). The ability of weather radar to detect migrating birds up to their flying altitudes (O'Bannon 1995; Jungbluth et al. 1995; Gauthreaux and Belser 1998; Zrnić and Ryzhkov 1998; Gauthreaux et al. 1998; Koistinen 2000; Collins 2001; Bi et al. 2002; van Gasteren et al. 2008; Holleman et al. 2008; Dokter et al. 2011; Farnsworth et al. 2015) motivated the ornithologists to use the existing weather radars networks to study

Corresponding author: Dr. B. Radhakrishna, rakibasivi@gmail.com birds' migration and their behavior in different seasons. Though weather radars are vital tools for ornithologists to study birds' migration at various spatial scales, the challenges in processing the enormous quantity of data that radar captures have constrained its application to a handful of studies (Gauthreaux et al. 2003; Buler and Diehl 2009; Buler et al. 2012; Buler and Dawson 2014).

Most of the algorithms for detecting bird echoes use radial velocity standard deviations within $6 \mathrm{~km}$ range as a discriminator in the radar data (Koistinen 2000; van Gasteren et al. 2008; Holleman et al. 2008; Dokter et al. 2011). These bird echoes can help birdwatchers estimate their population (Nebuloni et al. 2008) during the migration period. The use of polarimetric parameters in identifying the birds and insects was demonstrated in Zhang et al. (2004) and birds and UAVs in Torvik et al. (2016). For example, birds possess higher differential phase and lower differential reflectivity than the insects.

A $20 \mathrm{dBZ}$ reflectivity threshold is often applied in identifying bird echoes (Dokter et al. 2011), one that may not be valid at $S$ band, the radar reflectivity values 
differing from one frequency to another due to resonance effect (Melnikov et al. 2012). For example, at S band in the present study, radar reflectivity values are observed up to $25 \mathrm{~dB} Z$ during the migration of birds. Even though the radial velocity standard deviation is a good discriminator for identifying bird returns, it is not sufficient during some instances as mentioned in Dokter et al. (2011). In some instances, biological and weather echoes are superposed, and their echo properties blended. In such cases, the target identification algorithms can fail and identify biological echoes as weather echoes (Stepanian et al. 2016). Hence, there is a need to design new algorithms using the advances in radar technology (polarimetric radars). The present study focuses on developing automated fuzzy logic algorithms for identifying radar returns from birds, precipitation and ground targets on a pixel-by-pixel basis from nonpolarimetric and polarimetric variables.

\section{Data}

The McGill radar functions much like radars in the WSR-88D network (i.e., similar frequency and simultaneous horizontal and vertical transmission). The McGill radar provides data every $5 \mathrm{~min}$ and the data are stored at a resolution of $1^{\circ} \times 1 \mathrm{~km}$ up to a range of $120 \mathrm{~km}$ and a resolution of $1^{\circ} \times 2 \mathrm{~km}$ from 120 to $240 \mathrm{~km}$. The radar parameters archived are reflectivity $Z$, radial Doppler velocity $V_{r}$, differential reflectivity $Z_{\mathrm{DR}}$, differential phase $\Phi_{\mathrm{DP}}$, (from which the specific differential phase $K_{\mathrm{DP}}$ is derived), and the correlation coefficient $\rho_{\mathrm{HV}}$. The signal and radar data processing was limited to averaging in range, thresholding based on signal quality index (SQI), velocity dealiasing, and range unfolding. In addition to the archival of the low-resolution volume scans, their standard deviations over the eight samples of the resolution volume are also archived. Except for Doppler velocity, the standard deviation is computed using

$$
\sigma_{x}=\sqrt{\overline{x^{2}}-\bar{x}^{2}}
$$

where $\bar{x}$ and $\overline{x^{2}}$ are the mean and squared mean values of the eight gates within the $1^{\circ} \times 1 \mathrm{~km}$ area. The Doppler velocity standard deviation $\sigma_{V_{r}}$ is computed from the eight $1^{\circ} \times 125 \mathrm{~m}$ gates Doppler velocities $v_{i}$ within the $1^{\circ} \times 1 \mathrm{~km}$ pixel and using the Nyquist velocity $v_{\text {nyq }}$ as follows:

$$
\sigma_{V_{r}}=\frac{\lambda}{\left(4 \pi t_{\text {ipp }}\right)} \sqrt{2 \log \left(\frac{1}{\sqrt{a^{2}+b^{2}}}\right)},
$$

with

$$
a=\frac{1}{8} \sum_{i=1}^{8} \cos \left(\frac{\pi v_{i}}{v_{\text {nyq }}}\right) \text { and } b=\frac{1}{8} \sum_{i=1}^{8} \sin \left(\frac{\pi v_{i}}{v_{\text {nyq }}}\right),
$$

where $\lambda$ is the radar wavelength ( $\mathrm{m} ; 0.1041 \mathrm{~m}$ for McGill radar) and $t_{\text {ipp }}$ is the inter pulse period (s). McGill radar scans are at $1200 \mathrm{~Hz}$ except for the first five even elevation angles. Equation (2), similar to the formula used to compute spectrum width from pulse pairs (e.g., Fabry 2015), estimates the spread of Doppler velocity in the $1^{\circ} \times 1 \mathrm{~km}$ pixel and provides good estimates even with aliased velocities.

Apart from $\sigma_{V_{r}}$ and spectral width, another derived dual-polarization parameter called SDR (Melnikov and Matrosov 2013), a proxy for circular depolarization ratio $(\mathrm{CDR})$, is also estimated utilizing $1^{\circ} \times 1 \mathrm{~km}$ pixels. Unlike the linear depolarization ratio (LDR) that strongly depends on particle shapes and orientations, CDR does not depend on particle orientation in the incident wave polarization plane (Matrosov et al. 2001). This makes CDR is a useful parameter for estimating shapes of radar targets that are often expressed in terms of their axis ratios. CDR measurements are possible only when radars employing the circular polarization scheme. Nowadays most of the radars employ linear polarization scheme. Thus, to make use of CDR in linear polarization scheme, Melnikov and Matrosov (2013) introduced this new polarimetric parameter SDR, which is estimated as follows:

$$
\mathrm{SDR}=\frac{Z_{\mathrm{DR}}+1-2 Z_{\mathrm{DR}}^{1 / 2} \rho_{\mathrm{HV}}}{Z_{\mathrm{DR}}+1+2 Z_{\mathrm{DR}}^{1 / 2} \rho_{\mathrm{HV}}}
$$

SDR is particularly useful at separating targets with regular or symmetric shapes like raindrops from targets with irregular shapes like birds or ground targets. Our study is limited to radar echoes within $120 \mathrm{~km}$ with a reflectivity greater than twice the noise level (noise level $+3 \mathrm{~dB}$ ), a level corresponding to a reflectivity of $6 \mathrm{dBZ}$ at $100 \mathrm{~km}$.

\section{Event description and membership functions}

A basic description of the events selected for our study is presented in Table 1 . They have been selected in such a way that the generated density distribution functions and associated membership functions are not contaminated by other types of radar returns. The data on 17 October 2012 consist of radar returns from only ground targets and birds. To generate density distributions of radar returns from only birds, the ground targets were removed using a clutter mask derived 
TABLE 1. Types of events used in the present study observed with McGill S-band radar and their durations. The boldface dates represents the events used to train the fuzzy logic algorithms.

\begin{tabular}{llc}
\hline \multicolumn{1}{c}{ Date } & Type of event observed & Duration (UTC) \\
\hline 17 Oct 2012 & Birds & $0200-0400$ \\
18 Sep 2012 & Precipitation & $1630-1830$ \\
10 Jan 2013 & Clear sky (clutter) & $1900-2100$ \\
30 May 2012 & Birds and precipitation & $0200-0400$ \\
17 Dec 2012 & $\begin{array}{l}\text { Precipitation with cloud } \\
\text { top }<4 \text { km }\end{array}$ \\
& & $1500-1600$ \\
\hline
\end{tabular}

by Zawadzki et al. (2001). The second event on 18 September 2012 consists of radar returns from stratiform and convective precipitation and from ground targets. The same clutter mask is applied to the radar data in order to remove the ground target returns prior the generation of the precipitation particles density distribution functions. For example, the density distribution of $Z$ during precipitation is obtained by counting the number of pixels each $Z$ interval and normalized with total number of pixels. Finally, the radar data archived on 10 January 2013 are mainly due to ground targets and are used to derive the ground clutter density distribution functions. In addition, in order to assess the applicability of the devised fuzzy logic algorithms, two independent events are chosen. These two events are not used in the generation of density distributions and of membership functions. The radar returns observed on 30 May 2012 is a bird migration event in which precipitation is also observed in the northeast sector of the radar coverage. A precipitation event on 17 December 2012 where radar returns are confined below $4 \mathrm{~km}$ altitude is also used as birds can fly up to an altitude of $4 \mathrm{~km}$ during their migration.

The normalized density distributions $f(x)$ generated for clutter, precipitation and birds radar returns are shown in Figs. 1 and 2 together with their associated membership functions $f_{m}(x)$. The membership functions are estimated using the following equation as indicated in Cho et al. (2006):

$$
f_{m}^{i}(x)=\frac{f^{i}(x)}{\sum_{i=1}^{3} f^{i}(x)}
$$

where the superscript $i=1,2$, and 3 represent ground clutter, precipitation and birds, respectively. The estimated $f_{m}(x)$ along with $f(x)$ for nonpolarimetric and polarimetric variables are portrayed in Figs. 1 and 2, respectively.

The reflectivity density distribution functions of ground targets, precipitation and birds have different widths with a considerable overlapping region. The observed reflectivity of birds is within -10 to $25 \mathrm{dBZ}$ at $\mathrm{S}$ band, whereas the range is wider for ground targets and precipitation particles and the upper limit can extend to $60 \mathrm{~dB} Z$. The range of Doppler velocity for ground targets is -3 to $3 \mathrm{~m} \mathrm{~s}^{-1}$ while for birds (in the present study) it extends from -15 to $15 \mathrm{~m} \mathrm{~s}^{-1}$, and for precipitation particles it is much more (i.e., from -30 to $30 \mathrm{~m} \mathrm{~s}^{-1}$ ). The Doppler velocity of ground targets underlines its quasi-stationary nature, which is useful information for their recognition, but this information is not sufficient because precipitation targets moving perpendicular to the radar beam also yield near-zero velocities. Since precipitation and birds are distributed targets for radar, their spectral width is also a good indicator for target identification. The distribution of the radar observed spectrum width reveals these values to be $<2.5 \mathrm{~m} \mathrm{~s}^{-1}$ for ground targets as they are quasi stationary when compared to precipitation $\left(<4 \mathrm{~m} \mathrm{~s}^{-1}\right)$ and birds $\left(<5 \mathrm{~m} \mathrm{~s}^{-1}\right)$.

Along with these radar-observed nonpolarimetric variables, other quantities like the standard deviation of the Doppler velocity and the vertical gradient of reflectivity (VGZ) are also used in our fuzzy logic algorithm. Dokter et al. (2011) utilized model atmospheric winds to compute standard deviation of Doppler velocities of birds and showed large standard deviation values, as birds' velocities are different from the atmospheric winds. When model computed atmospheric winds are different from the observed winds, the standard deviation of Doppler velocities is large (Dokter et al. 2011). In parallel, the VGZ is calculated from the following:

$$
\mathrm{VGZ}=\frac{\mathrm{dB} Z_{x}-\mathrm{dB} Z_{x+2}}{\theta_{x+2}-\theta_{x}},
$$

where the subscript $x$ refers to the elevation angle number. In the specific case of the McGill radar that switches PRF between successive scans, the vertical gradient was computed between scans with identical PRF to avoid possible artifacts arising from PRF changes. Thus, VGZs are computed from $x$ and $x+2$ elevations instead of $x$ and $x+1$ following Cho et al. (2006). As seen from Fig. 1, $\sigma_{V_{r}}$ of precipitation and ground echoes show similar distributions but are different for birds. The $\sigma_{V_{r}}$ values are small for precipitation and clutter $\left(<6 \mathrm{~m} \mathrm{~s}^{-1}\right)$ but large for birds $\left(<9 \mathrm{~m} \mathrm{~s}^{-1}\right)$. The normalized density distribution $f(x)$ of VGZ for precipitation is symmetrically distributed centered at $0 \mathrm{~dB} Z \mathrm{deg}^{-1}$ whereas ground echoes show two distributions that are similar to Cho et al. (2006). On the other hand, the $f(x)$ of VGZ for birds is not 

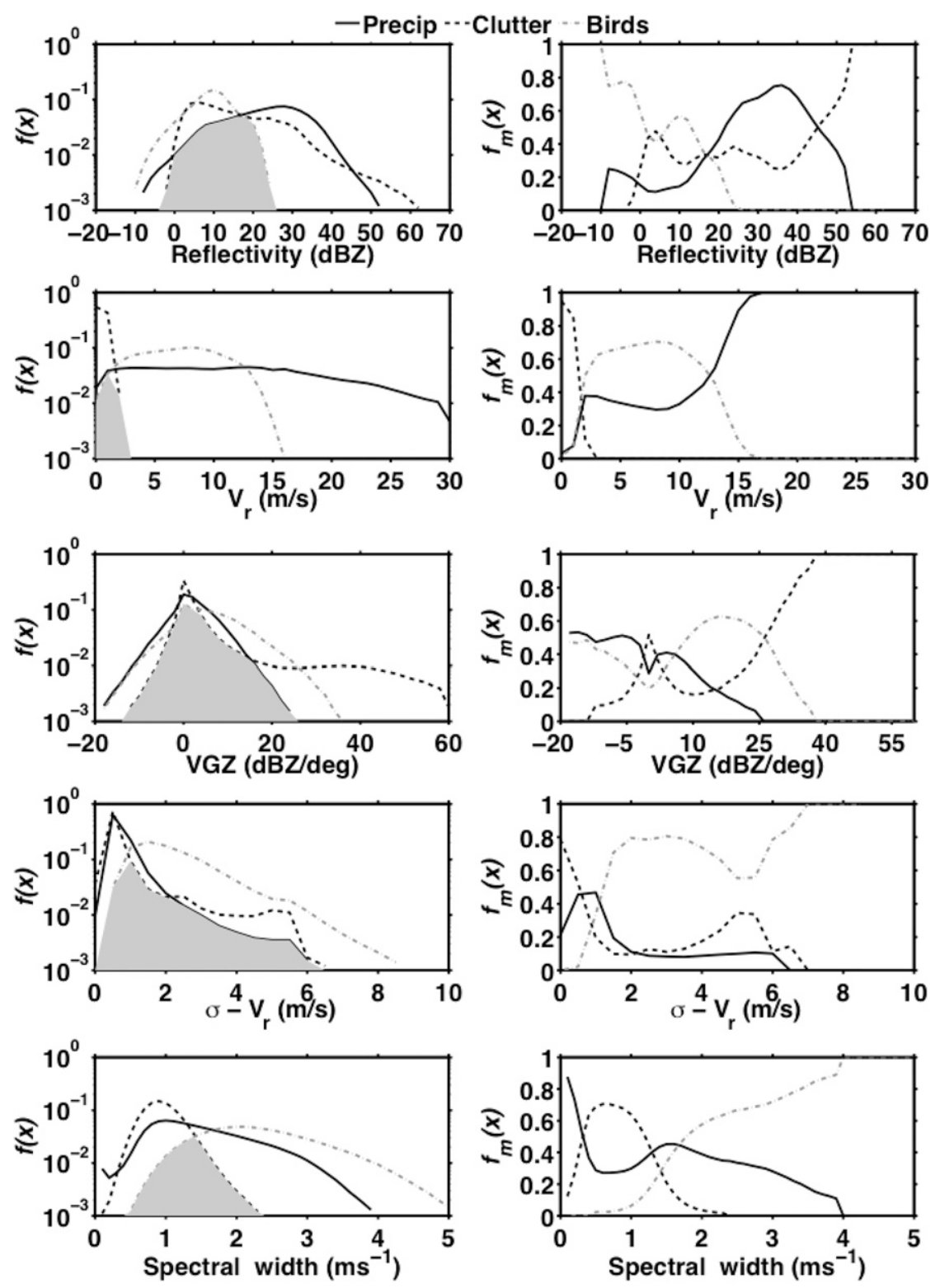

FIG 1. Normalized density distributions $f(x)$ and estimated membership functions $f_{m}(x)$ of radar observed and derived nonpolarimetric variables from precipitation (black solid line), ground targets (black dashed line), and birds (gray dash-dotted line). The gray shading indicates the overlapping area of the three normalized density distribution curves.

symmetrical and is skewed toward the positive values indicating the decrease of reflectivity with height as the birds number density decreases with increasing altitude.

Figure 2 depicts the $f(x)$ and $f_{m}(x)$ of polarimetric variables, namely, correlation coefficient $\rho_{\mathrm{HV}}$, differential reflectivity $Z_{\mathrm{DR}}$, differential phase shift $\Phi_{\mathrm{DP}}$ and the standard deviations of $Z_{\mathrm{DR}}\left(\sigma_{Z_{\mathrm{DR}}}\right)$ and $\Phi_{\mathrm{DP}}\left(\sigma_{\Phi_{\mathrm{DP}}}\right)$. Polarimetric variables show narrower distribution of $f(x)$ for precipitation when compared to those for birds and ground echoes. As indicated by Zrnić and Ryzhkov (1998), $\rho_{\mathrm{HV}}$ is higher for precipitation when compared with ground targets and biological scatters. Similarly, the peak in $\rho_{\mathrm{HV}}$ values for precipitation at 1 concurs with previous studies. This peak shifts toward smaller values for ground targets (0.8) and birds (0.6). The $Z_{\mathrm{DR}}$ values for precipitation show a narrow distribution within the -1 to $3 \mathrm{~dB}$ interval while those for birds $(-5$ to $5 \mathrm{~dB})$ and ground targets $(-9$ to $6 \mathrm{~dB})$ are more widely distributed. Similar to $Z_{\mathrm{DR}}$, in the 

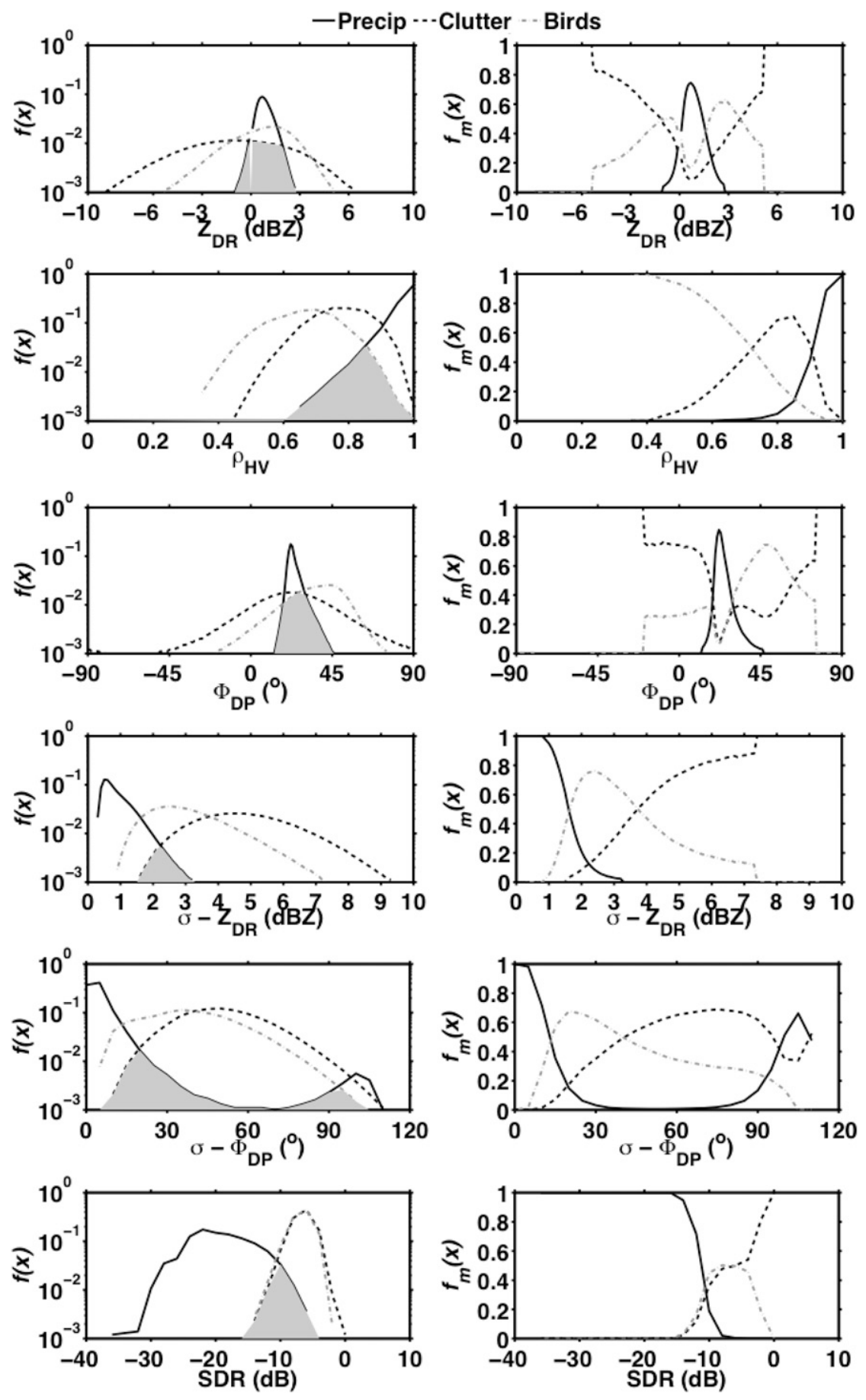

FIG. 2. As in Fig. 1, but for polarimetric variables.

present study $\Phi_{\mathrm{DP}}$ also shows a narrow distribution for precipitation $\left(10^{\circ}\right.$ to $\left.40^{\circ}\right)$ and wider distributions for birds $\left(-20^{\circ}\right.$ to $\left.70^{\circ}\right)$ and ground targets $\left(-45^{\circ}\right.$ to $\left.90^{\circ}\right)$. The normalized frequency distributions of standard deviation of $Z_{\mathrm{DR}}$ and $\Phi_{\mathrm{DP}}$ also depict similar features as for $Z_{\mathrm{DR}}$ and $\Phi_{\mathrm{DP}}$. In precipitation, the values of $\sigma_{Z_{\mathrm{DR}}}$ and $\sigma_{\Phi_{\mathrm{DP}}}$ are less than $3 \mathrm{~dB}$ and $40^{\circ}$, respectively. Compared to precipitation, the distribution of $\sigma_{Z_{\mathrm{DR}}}(0$ to $3 \mathrm{~dB}$ for precipitation, 1 to $7 \mathrm{~dB}$ for birds, and 1.5 to $9 \mathrm{~dB}$ for clutter) is broader for birds and clutter and approximately the same for $\sigma_{\Phi_{\mathrm{DP}}}\left(0^{\circ}\right.$ to $110^{\circ}$ ). Consequently, polarimetric variables are better than nonpolarimetric variables for target identification. 


\section{Fuzzy logic algorithms}

Two separate fuzzy logic algorithms are devised using either the membership functions of nonpolarimetric or of polarimetric variables for identifying radar echoes. The relative importance or weight of each membership function is inversely proportional to the overlapping area of the density distributions since an increase in the overlapping area decreases the ability to distinguish the targets. The weights are computed following Cho et al. (2006) as follows:

$$
w_{j}=\frac{1}{A_{j}} \sum_{j=1}^{k} \frac{1}{A_{j}},
$$

where $k$ refers to number of membership functions used in the fuzzy logic and $A_{j}$ is the overlapping area of $f(x)$ for birds, precipitation and ground clutter. The overlapping area for each fuzzy logic membership function is represented with the gray shades in Figs. 1 and 2. The smaller the overlapping area, the larger the weight a parameter is given as it is more useful for segregating the targets. The density functions are normalized so that the areas under the distribution curves are equal to 1 and the overlapping area is always less than 1 . The weights shown in Table 2 are divided by 100 due to their large values at low overlapping areas. These weights and membership functions are used in the computation of the aggregation value $Q$ for birds, precipitation and clutter at each radar pixel as follows:

$$
Q_{i}=\frac{\sum_{j=1}^{k}\left[f_{m}^{i}\left(x_{j}\right) w_{j}\right]}{\sum_{j=1}^{k} w_{j}},
$$

where $i$ refers to the type of echo (birds or precipitation or clutter) and $k$ is the number of the membership functions used in the fuzzy logic algorithm. Based on the aggregation scores at each pixel, the pixel is assigned to either precipitation or clutter or birds based on the following condition:

$$
\operatorname{TID}=\max \left(Q_{\text {precip }}, Q_{\text {birds }}, Q_{\text {clutter }}\right),
$$

where TID refers to target identified.

The nonpolarimetric fuzzy logic algorithm uses $Z$ $(\mathrm{dB} Z), V_{r}\left(\mathrm{~m} \mathrm{~s}^{-1}\right), \sigma_{V_{r}}\left(\mathrm{~m} \mathrm{~s}^{-1}\right), \operatorname{VGZ}\left(\mathrm{dBZ} \mathrm{deg}^{-1}\right)$, and spectral width $\left(\mathrm{ms}^{-1}\right)$ as membership functions. On the other hand, the membership functions utilized in polarimetric fuzzy logic algorithm are spectral width $\left(\mathrm{m} \mathrm{s}^{-1}\right), \sigma_{V_{r}}\left(\mathrm{~m} \mathrm{~s}^{-1}\right), Z_{\mathrm{DR}}(\mathrm{dB}), \rho_{\mathrm{HV}}, \Phi_{\mathrm{DP}}\left(^{\circ}\right), \sigma_{\Phi_{\mathrm{DP}}}\left({ }^{\circ}\right)$, $\sigma_{Z_{\mathrm{DR}}}(\mathrm{dB})$, and SDR. As the weights of $Z, V_{r}$, and
TABLE 2. Estimated weights of the membership functions in polarimetric and nonpolarimetric fuzzy logic. The normalized weights are given in the parentheses.

\begin{tabular}{lcc}
\hline \multirow{2}{*}{\multicolumn{1}{c}{ Parameter }} & \multicolumn{2}{c}{ Weight } \\
\cline { 2 - 3 } & Polarimetric & Without polarimetric \\
\hline Reflectivity $(\mathrm{dB} Z)$ & - & $1.0(0.086)$ \\
Doppler velocity $\left(\mathrm{m} \mathrm{s}^{-1}\right)$ & - & $6.72(0.576)$ \\
$\sigma_{V_{r}}\left(\mathrm{~m} \mathrm{~s}^{-1}\right)$ & $3.76(0.054)$ & $1.6(0.137)$ \\
Spectral width $\left(\mathrm{m} \mathrm{s}^{-1}\right)$ & $4.23(0.061)$ & $1.73(0.149)$ \\
$\rho_{\mathrm{HV}}$ & $11.03(0.158)$ & - \\
$Z_{\mathrm{DR}}(\mathrm{dB})$ & $3.23(0.046)$ & - \\
$\Phi_{\mathrm{DP}}\left({ }^{\circ}\right)$ & $2.95(0.042)$ & - \\
$\sigma_{Z_{\mathrm{DR}}}(\mathrm{dB})$ & $17.98(0.257)$ & - \\
$\left.\sigma_{\Phi_{\mathrm{DP}}}{ }^{\circ}\right)$ & $13.31(0.19)$ & - \\
$\mathrm{SDR}$ & $13.4(0.192)$ & $0.61(0.052)$ \\
$\mathrm{VGZ}\left(\mathrm{dB} Z \mathrm{deg}^{-1}\right)$ & - & \\
\hline
\end{tabular}

VGZ are small (not shown here), these membership functions are not considered in the polarimetric fuzzy logic algorithm. The estimated weights of these membership functions are given in Table 2. In accordance with Fig. 1, the membership function of the Doppler velocity is the most weighted in the nonpolarimetric algorithm $(57.6 \%)$ followed by spectral width $(14.9 \%)$, $\sigma_{V_{r}}(13.7 \%), Z(8.6 \%)$, and VGZ $(5.2 \%)$ is weighted the least. However, for polarimetric case $\sigma_{Z_{\mathrm{DR}}}(25.7 \%)$ is weighted the most followed by SDR $(19.2 \%), \sigma_{\Phi_{\mathrm{DP}}}$ $(19 \%), \rho_{\mathrm{HV}}(15.8 \%)$, spectral width $(6.1 \%), \sigma_{V_{r}}(5.4 \%)$, $Z_{\mathrm{DR}}(4.6 \%)$, and $\Phi_{\mathrm{DP}}(4.2 \%)$ is weighted the least. When compared to $\sigma_{V_{r}}$, the standard deviations of the polarimetric membership functions are more weighted by a factor of 5 indicating that the standard deviation of the polarimetric variables are better indicators for TID than the $\sigma_{V_{r}}$.

The fuzzy logic algorithms may lead to erroneous identifications when the $f_{m}(x)$ values of a pixel are in the overlapping region of the $f(x)$ curves. To overcome this, a few subjective conditions are imposed on the outcome of Eq. (8) following Gourley et al. (2007). These subjective conditions, drawn from the $f(x)$ curves in the form of threshold values, are provided in Table 3. Along with these, an additional condition called echo top (ET), defined as the maximum height till the radar return signal power is above the noise level, is also used for improving bird identification because they migrate below $4 \mathrm{~km}$ altitude (Dokter et al. 2011). A pixel where the membership function values does not satisfy all the imposed conditions for birds, precipitation and clutter is classified as a "mixed echo."

\section{Results}

The devised fuzzy logic algorithms are tested on the McGill S-band radar data during different 
TABLE 3. Threshold values of radar parameters drawn from the density distribution functions to correct the false alarms.

\begin{tabular}{lccc}
\hline \hline & \multicolumn{3}{c}{$\begin{array}{c}\text { Range of values used to correct } \\
\text { false alarms }\end{array}$} \\
\cline { 2 - 4 } \multicolumn{1}{c}{ Parameter } & Clutter & Precipitation & Birds \\
\hline Reflectivity $(\mathrm{dBZ})$ & - & - & $<30$ \\
Doppler velocity $\left(\mathrm{m} \mathrm{s}^{-1}\right)$ & -3 to 3 & - & - \\
$\sigma_{V_{r}}\left(\mathrm{~m} \mathrm{~s}^{-1}\right)$ & $<6$ & $<6$ & - \\
Spectral width $\left(\mathrm{m} \mathrm{s}^{-1}\right)$ & $<2.5$ & $<4$ & - \\
$Z_{\mathrm{DR}}(\mathrm{dB})$ & - & -1 to 3 & - \\
$\Phi_{\mathrm{DP}}\left({ }^{\circ}\right)$ & - & 10 to 50 & - \\
$\sigma_{Z_{\mathrm{DR}}}(\mathrm{dB})$ & $>1.5$ & $<3$ & $>0.7$ \\
$\sigma_{\Phi_{\mathrm{DP}}}\left({ }^{\circ}\right)$ & - & $<50$ & - \\
Echo top $(\mathrm{km})$ & - & - & $<4$ \\
\hline
\end{tabular}

meteorological conditions. The radar observed and derived parameters and outcome of the two fuzzy logic algorithms at $0.5^{\circ}$ elevation angle are shown in Figs. 3-7. PPIs of radar parameters at 1904 UTC 10 January 2013 and the TID obtained from the two different fuzzy logic techniques are depicted in Fig. 3. The nomenclatures TID (nonpolarimetric) and TID (polarimetric) used in Fig. 3 indicate the fuzzy logic algorithms designed with nonpolarimetric and polarimetric membership functions, respectively. This first event is a meteorologically clear day and the radar returns are only from ground targets. The outcome of the fuzzy logic algorithms shows that both algorithms are identifying the ground echoes properly. Getting confidence on these algorithms, we have used TID (polarimetric) to remove the ground clutter (with minimum false alarms) in order to estimate the false alarms in the TID.

At 0239 UTC 17 October 2012, the very highfrequency (VHF) wind profiler observations (not shown here), collocated to the McGill S-band weather radar, show northeasterly winds below $6 \mathrm{~km}$ altitude and the surface observations report no rain. However, the S-band radar volume scans depict radar reflectivity values up to $25 \mathrm{~dB} Z$, which indicates the presence of nonmeteorological targets (migrating birds) up to $4 \mathrm{~km}$ altitude. The observed radial velocities shown in Fig. 4 indicate birds are migrating from northeast to southwest direction by taking the advantage of the prevailing wind. The polarimetric observations of migrating birds are distinctly different in various directions depending on many conditions (such as bird orientation, density and scattering mechanism) and a detailed research on this aspect is beyond the scope of this study. TID obtained from both algorithms are depicted in the bottom row of Fig. 4; they show that TID (nonpolarimetric) and TID (polarimetric) are identifying the targets with great accuracy. The TID (polarimetric) generally performs better than the TID (nonpolarimetric) as it has fewer false alarms.

The outcomes of the devised fuzzy logic algorithms on rainy days such as 1629 UTC 18 September 2012 are shown in Fig. 5. In this event, TID (nonpolarimetric) encounter problems in the region of zero isodop (the region where the radial velocity become zero). Within the zero isodop, though the echoes are observed from precipitation, the devised TID (nonpolarimetric) identifies them as ground echoes. This could be due to the heavy weight given to the Doppler velocity $(57.6 \%)$ in the fuzzy logic of TID (nonpolarimetric). However, fuzzy logic TID (polarimetric) identifies the targets with great accuracy even in the zero isodop.

As explained in section 2, along with migrating birds, strong convective precipitation is observed $30 \mathrm{~km}$ from the radar site in the northeast quadrant on 30 May 2012. Wind profilers and surface meteorological stations show prevailing winds coming from the southwest during the observation period. The radar observed Doppler velocity also shows that the birds are migrating from southwest to the northeast. The radar parameters including the fuzzy logic algorithms output for this event are depicted in Fig. 6. It is very interesting to note that the birds are staying in the trailing edge of the precipitation and the migration follows the precipitation motion. When migrating birds approach the radar, they show polarimetric features similar to those seen in the radar observations on 17 October 2012. As also mentioned earlier, the TID (nonpolarimetric) shows few false alarms in the zero isodop (extreme north to the radar site) where actually a convective cell is persisting. Nevertheless, these false alarms are identified correctly by the TID (polarimetric), but both the fuzzy logics show a few false alarms at the edges of the observed patterns.

One of the subjective criteria used in identifying birds is the $4 \mathrm{~km}$ altitude threshold. Hence, we want to test the applicability of these algorithms for a shallow precipitation event (i.e., when precipitation echo returns are confined below $4 \mathrm{~km}$ altitude). For this purpose, a shallow precipitation event observed on 17 December 2012 is considered. On this day, measurements from vertically pointing $\mathrm{X}$-band radar, located $18.5 \mathrm{~km}$ east to radar site, show an echo-top height of $\sim 4.5 \mathrm{~km}$ during the entire event. The radar reflectivity indicates a strong precipitation cell on the western side of the radar site with widespread precipitation around it. In this event, the TID (nonpolarimetric) has failed to identify the targets, but the TID (polarimetric) has a good skill except at the edges of the precipitation cell. On the edges, the quality of the radar returns degrades, which in turn affects the TID. Correcting these false alarms at the edges of the patterns where data quality is poor will be carried out in the near future. 


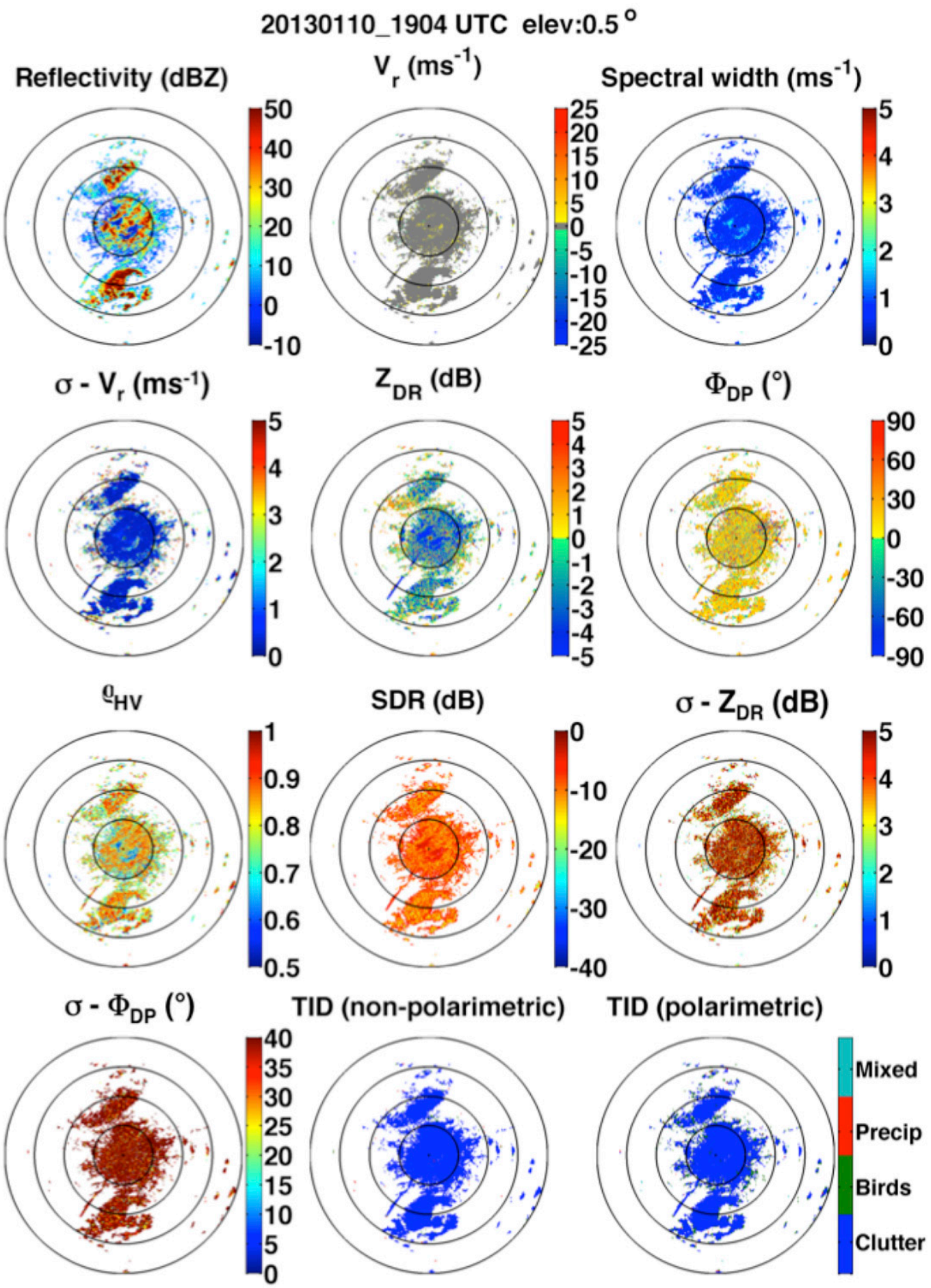

FIG. 3. PPIs of McGill S-band dual-polarization radar at an elevation of $0.5^{\circ}$. PPIs indicate radar-observed and radar-derived products along with TID information obtained from two different algorithms at 1904 UTC 10 Jan 2013. TID (nonpolarimetric) and TID (polarimetric) indicate fuzzy logic devised using nonpolarimetric and polarimetric membership functions, respectively. The overlaid black circles are the $30 \mathrm{~km}$ range intervals. 
20121017_0239 UTC elev:0.5 ${ }^{\circ}$

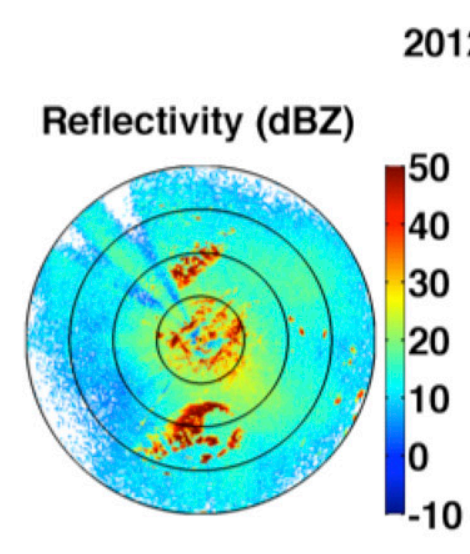

$\mathrm{v}_{\mathrm{r}}\left(\mathrm{ms}^{-1}\right)$
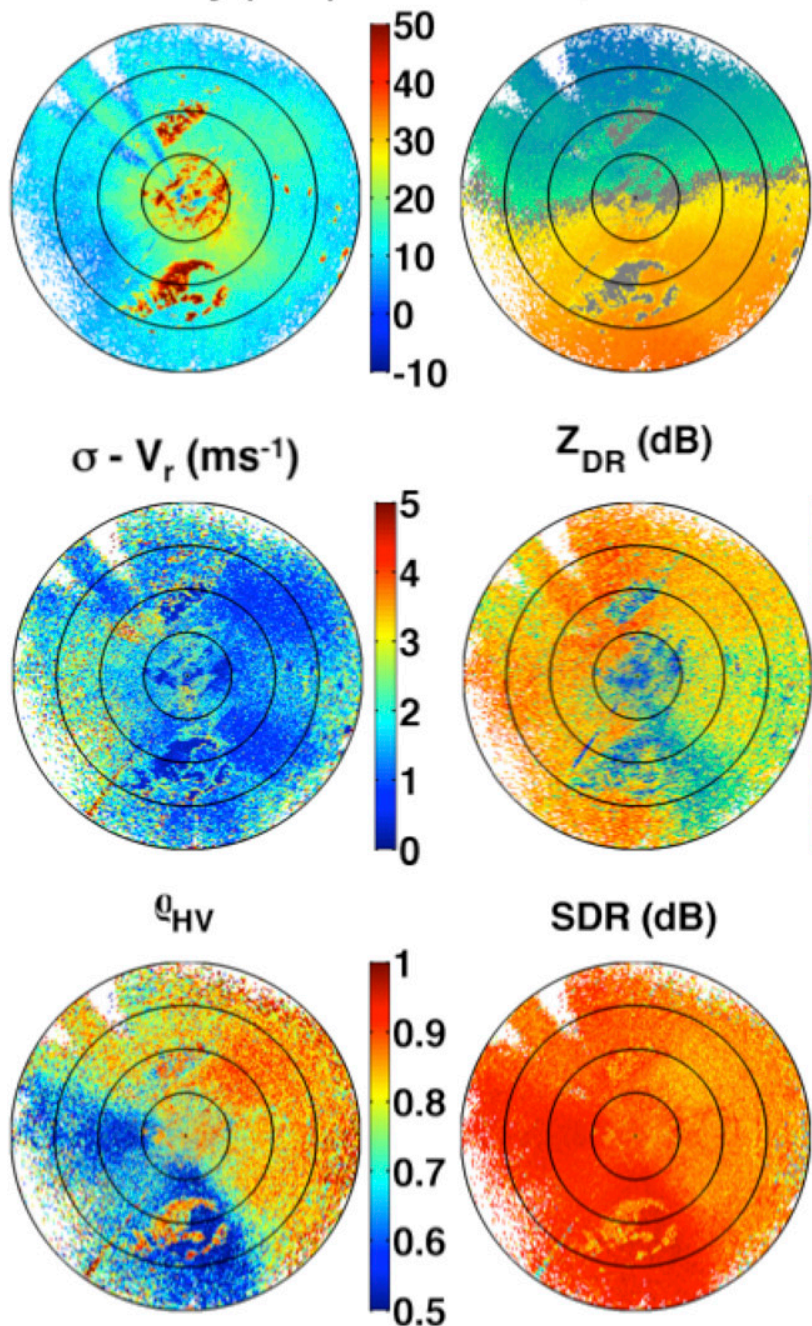

$\sigma-\Phi_{\mathrm{DP}}\left({ }^{\circ}\right)$

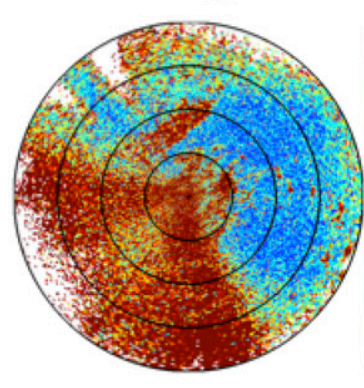

$\mathrm{Z}_{\mathrm{DR}}(\mathrm{dB})$
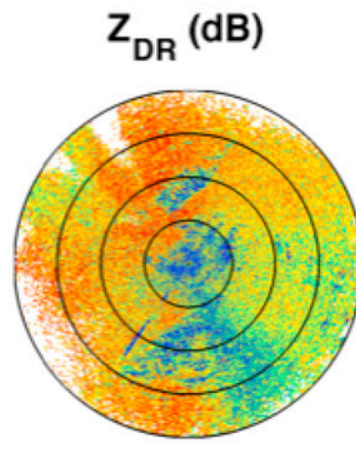

SDR (dB)
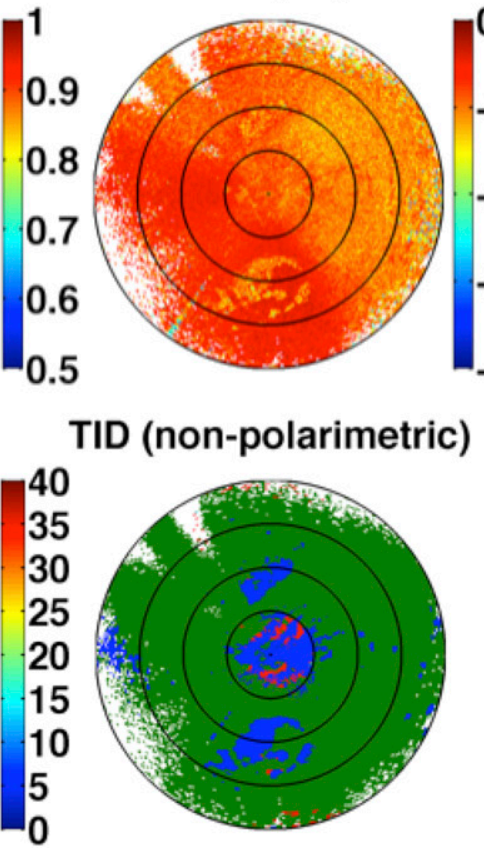

Spectral width $\left(\mathrm{ms}^{-1}\right)$
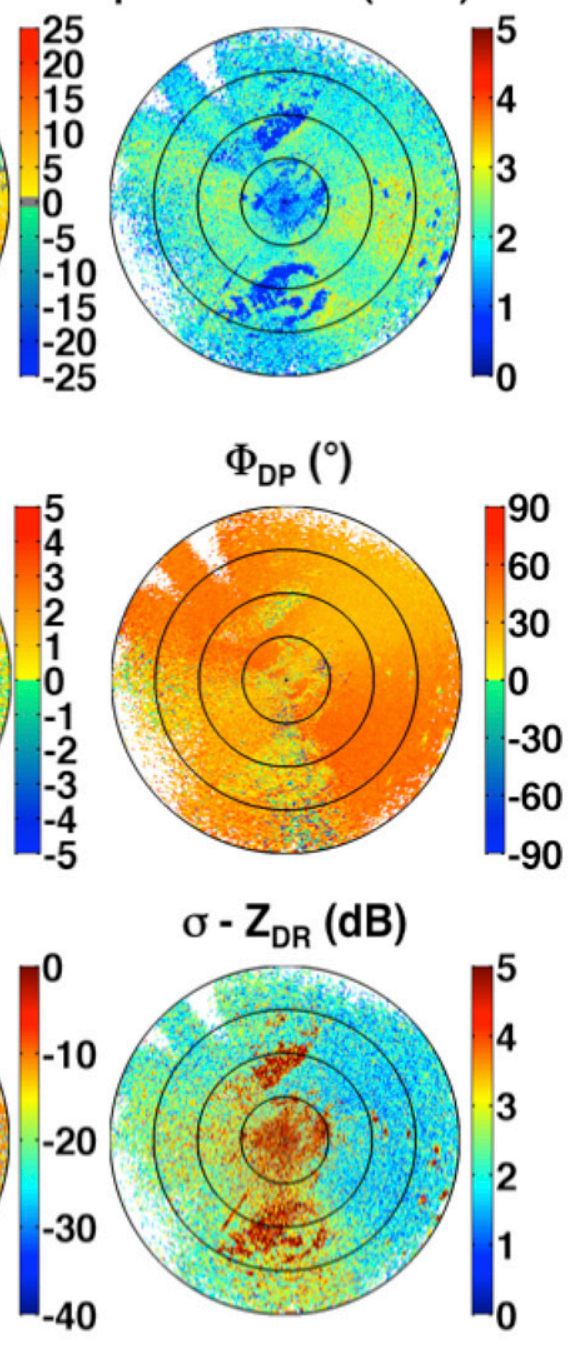

$\sigma-Z_{D R}(d B)$

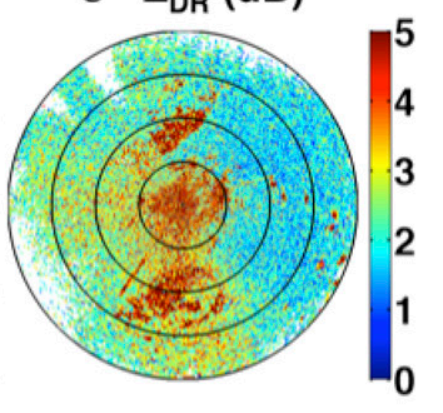

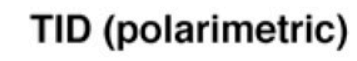

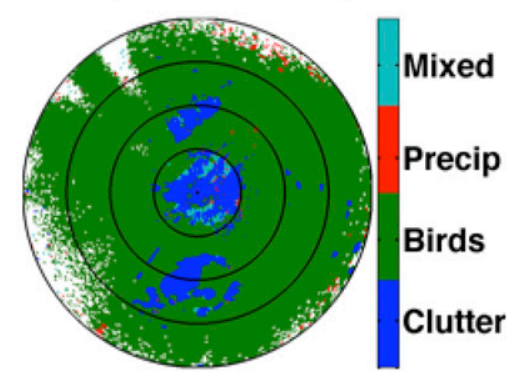

FIG. 4. As in Fig. 3, but for 0239 UTC 17 Oct 2012.

The aforementioned events are also used in generating the membership functions and hence the validity of the newly devised fuzzy logic algorithms is tested with two more events. The performance of TID (nonpolarimetric) and TID (polarimetric) algorithms are summarized in Table 4 based on the occurrence percentage of false alarms in identifying the targets. The occurrence percentage of false alarms is estimated from two 


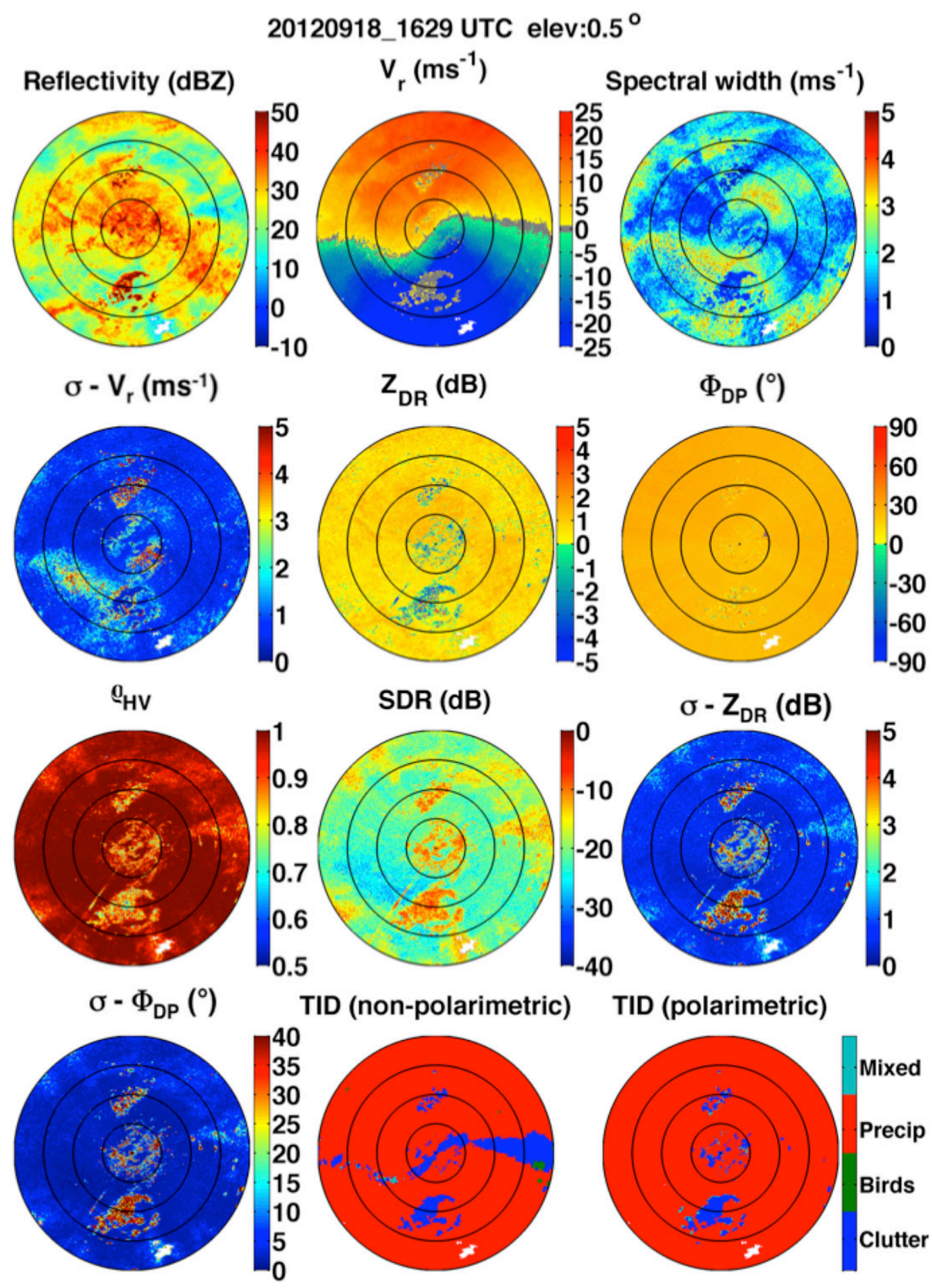

FIG. 5. As in Fig. 3, but for 1629 UTC 18 Sep 2012.

events observed on 18 September (precipitation and clutter) and 17 October 2012 (migrating birds and clutter). The total number of radar data pixels observed during each event is also presented in Table 4. The output of the TID (nonpolarimetric) contains $\sim 10 \%$ false alarms when identifying precipitation and birds. However, the output of the TID (polarimetric) shows only $\sim 2 \%$ false alarms during the precipitation event and $\sim 0.9 \%$ in the birds migration event. This provides strong evidence that the TID algorithm devised 


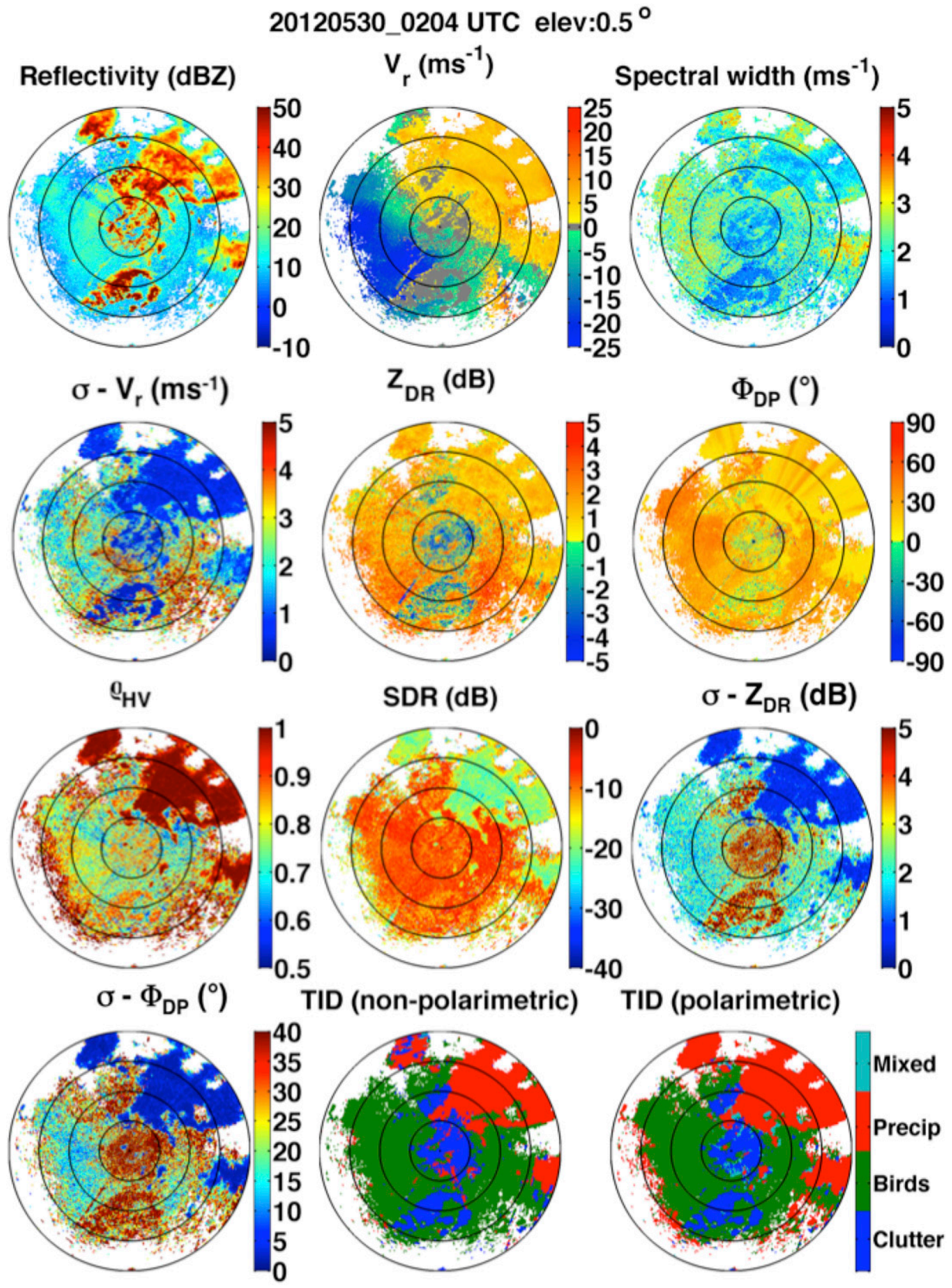

FIG. 6. As in Fig. 3, but for 0204 UTC 30 May 2012.

using polarimetric membership functions has a better skill when compared to the nonpolarimetric one.

The sensitivity analysis is extended further for the TID polarimetric by including additional parameters $\left(Z, V_{r}\right.$, and VGZ) and removing the subjective conditions.
Results indicate that, after including the radar parameters $Z, V_{r}$, and VGZ in the TID polarimetric fuzzy logic, the false alarms are reduced from $0.92 \%$ to $0.53 \%$ for the bird's passage event and from $1.99 \%$ to $1.72 \%$ for the precipitation event. As also mentioned in section 3, along 


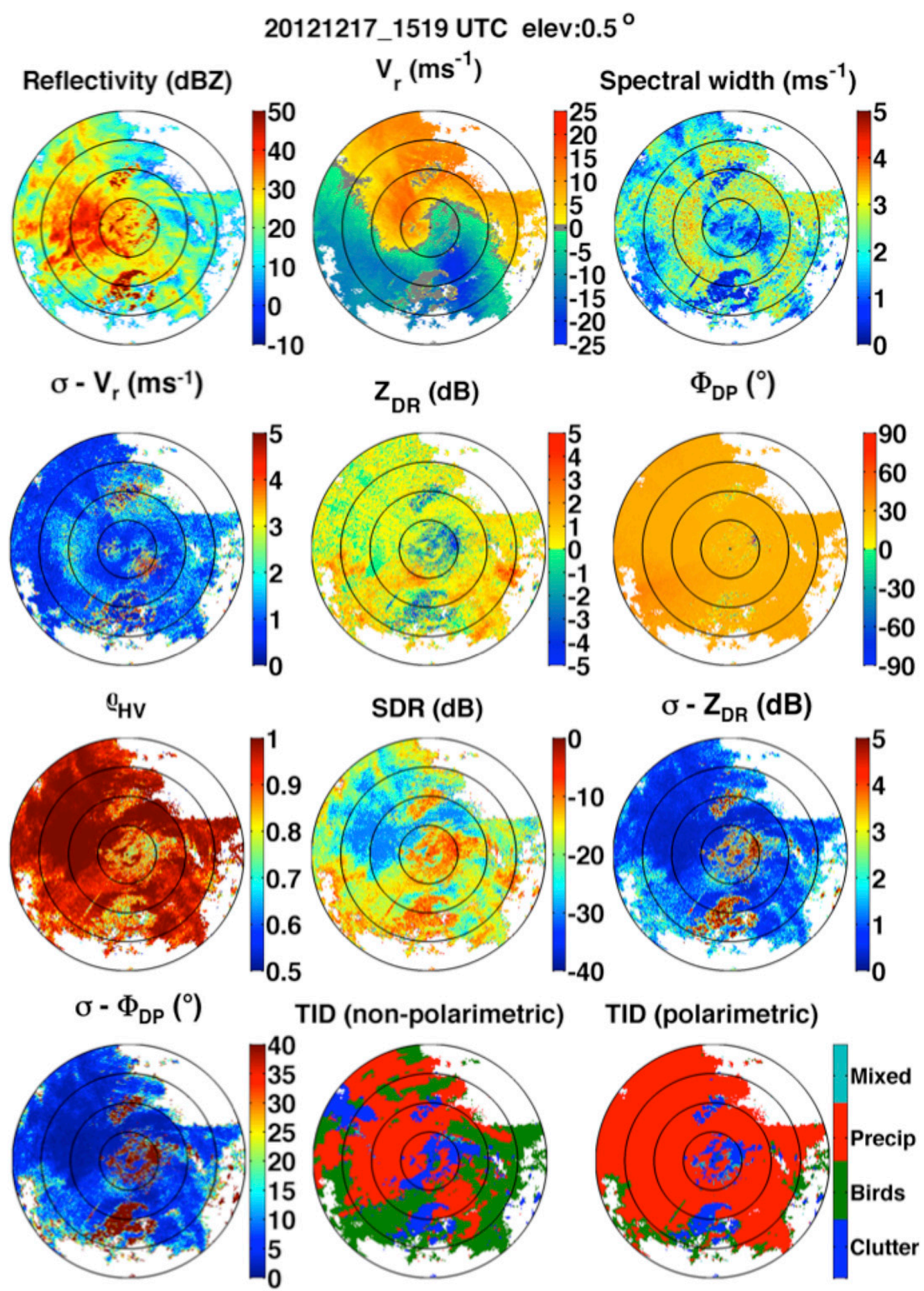

FIG. 7. As in Fig. 3, but for 1519 UTC 17 Dec 2012.

with the small weights, the improvements seen in the false alarms are minor after including these three parameters. Hence, $Z, V_{r}$, and VGZ are not considered in the TID polarimetric case. More importantly, removing the subjective conditions considerably raises the false alarm rate of the TID polarimetric algorithm from $0.92 \%$ to $11 \%$ for the bird passage event and from $1.99 \%$ to $5.3 \%$ for the precipitation event. 
TABLE 4. The occurrence percentage of false alarms (\%) found in the newly devised fuzzy logic algorithms. SNR is signalto-noise ratio.

\begin{tabular}{lccc}
\hline \hline & \multicolumn{2}{c}{ False alarms (\%) } & Total number of \\
\cline { 2 - 3 } $\begin{array}{c}\text { Observed } \\
\text { type of event }\end{array}$ & $\begin{array}{c}\text { Nonpolarimetric } \\
\text { variables }\end{array}$ & $\begin{array}{c}\text { Polarimetric } \\
\text { variables }\end{array}$ & $\begin{array}{c}\text { pixels with } Z> \\
(\text { SNR }=3 \mathrm{~dB})\end{array}$ \\
\hline Precipitation & 10.12 & 1.99 & 15697712 \\
Birds & 9.6 & 0.92 & 9240822 \\
\hline
\end{tabular}

\section{Conclusions}

Pixel-oriented fuzzy logic algorithms are devised to identify targets that cause radar returns. The fuzzy logic algorithms are straight forward and easy to implement for the operational radar networks when compared to the advanced algorithms that classify by learning, clustering, and signal separation. Hence, two separate algorithms are developed using nonpolarimetric and polarimetric membership functions. The analysis of their performance indicates the following:

1) Though nonpolarimetric radar membership functions are adequate for separating radar returns from birds, precipitation, and ground targets, they are not sufficient. The nonpolarimetric case fails mainly in the regions of zero isodop and during precipitation with cloud top less than $4 \mathrm{~km}$ in our case.

2) Examining $2 \mathrm{~h}$ of volume scan radar data, it is found that the percentage of false alarms during precipitation and bird migration events are 10.12 and 9.6, respectively, for the TID (nonpolarimetric), and 1.99 and 0.92 , respectively, for the TID (polarimetric).

3) Radar observations of migrating birds show distinctly different polarimetric features during their relative approach and departure from the radar site indicating the dependency of radar parameters on the canting angle and scattering cross section.

Acknowledgments. This project was undertaken with the financial support of the Government of Canada provided through the Department of the Environment through Contract KM031-101302/001/TOR. A special thanks goes to all our group members, especially to Prof. Isztar Zawadzki for the fruitful discussions during the group meetings. The authors would like to thank the three anonymous reviewers for their critical review that improved the quality of the manuscript.

\section{REFERENCES}

Bachmann, S., and D. Zrnić, 2007: Spectral density of polarimetric variables separating biological scatterers in the VAD display. J. Atmos. Oceanic Technol., 24, 1186-1198, https://doi.org/ 10.1175/JTECH2043.1.
Bi, L., A. Shapiro, P. Zhang, and Q. Xu, 2002: Quality control problems for VAD winds and NEXRAD level-II winds in the presence of migrating birds. Preprints, 19th Conf. on Weather Analysis and Forecasting/15th Conf. on Numerical Weather Prediction, San Antonio, TX, Amer. Meteor. Soc., 143-145.

Buler, J. J., and R. H. Diehl, 2009: Quantifying bird density during migratory stopover using weather surveillance radar. IEEE Trans. Geosci. Remote Sens., 47, 2741-2751, https://doi.org/ 10.1109/TGRS.2009.2014463.

— , and D. K. Dawson, 2014: Radar analysis of fall bird migration stopover sites in the northeastern US. Condor, 116, 357-370, https://doi.org/10.1650/CONDOR-13-162.1.

_ L. A. Randall, J. P. Fleskes, W. C. Barrow Jr., T. Bogart, and D. Kluver, 2012: Mapping wintering waterfowl distributions using weather surveillance radar. PLOS ONE, 7, e41571, https://doi.org/10.1371/journal.pone.0041571.

Cho, Y. H., G. Lee, K. E. Kim, and I. Zawadzki, 2006: Identification and removal of ground echoes and anomalous propagation using the characteristics of radar echoes. J. Atmos. Oceanic Technol., 23, 1206-1222, https://doi.org/10.1175/JTECH1913.1.

Collins, W. G., 2001: The quality control of velocity azimuth display (VAD) winds at the National Centers for Environmental Prediction. Preprints, 11th Symp. on Meteorological Observations and Instrumentation, Albuquerque, NM, Amer. Meteor. Soc., 317-320.

Dokter, A. M., F. Liechti, H. Stark, L. Delobbe, P. Tabary, and I. Holleman, 2011: Bird migration flight altitudes studied by network of operational weather radars. J. Roy. Soc. Interface, 8, 30-43, https://doi.org/10.1098/rsif.2010.0116.

Fabry, F., 2015: Radar Meteorology-Principles and Practice. Cambridge University Press, 256 pp.

Farnsworth, A., B. M. Van Doren, W. M. Hochachka, D. Sheldon, K. Winner, J. Irvine, J. Geevarghese, and S. Kelling, 2015: A characterization of autumn nocturnal migration detected by weather surveillance radars in the northeastern US. Ecol. Appl., 26, 752-770, https://doi.org/10.1890/15-0023.

Gauthreaux, S. A., Jr., and C. G. Belser, 1998: Displays of bird movements on the WSR-88D: Patterns and quantification. Wea. Forecasting, 13, 453-464, https://doi.org/10.1175/15200434(1998)013<0453:DOBMOT>2.0.CO;2.

_ D. S. Mizarhi, and C. G. Belser, 1998: Bird migration and bias of WSR-88D wind estimates. Wea. Forecasting, 13, 465-481, https://doi.org/10.1175/1520-0434(1998)013<0465:BMABOW> 2.0.CO;2.

- C. G. Belser, and D. Van Blaricom, 2003: Using a network of WSR-88D weather surveillance radars to define patterns of bird migration at large spatial scales. Avian Migration, Springer-Verlag, 335-346.

Gourley, J. J., P. Tabary, and J. Parent du Chatelet, 2007: A fuzzy logic algorithm for the separation of precipitating from nonprecipitating echoes using polarimetric radar observations. J. Atmos. Oceanic Technol., 24, 1439-1451, https://doi.org/ 10.1175/JTECH2035.1.

Holleman, I., H. van Gasteren, and W. Bouten, 2008: Quality assessment of weather radar wind profiles during bird migration. J. Atmos. Oceanic Technol., 25, 2188-2198, https://doi.org/ 10.1175/2008JTECHA1067.1.

Jungbluth, K., J. Belles, and M. Schumacher, 1995: Velocity contamination of WSR-88D and wind profiler data due to migrating birds. Preprints, 27th Conf. on Radar Meteorology, Vail, CO, Amer. Meteor. Soc., 666-668.

Kilambi, A., F. Fabry, and V. Meunier, 2018: A Simple and effective method for separating meteorological from nonmeteorological 
targets using dual-polarization data. J. Atmos. Oceanic Technol., 35, 1415-1424, https://doi.org/10.1175/JTECH-D-17-0175.1.

Koistinen, J., 2000: Bird migration patterns on weather radar. Phys. Chem. Earth, 25B, 1185-1194, https://doi.org/10.1016/S14641909(00)00176-3.

Liu, S., Q. Xu, and P. Zhang, 2005: Identifying Doppler velocity contamination caused by migrating birds. Part II: Bayes identification and probability tests. J. Atmos. Oceanic Technol., 22, 1114-1121, https://doi.org/10.1175/JTECH1758.1.

Matrosov, S., R. F. Reinking, R. A. Kropfli, B. E. Martner, and B. W. Bartram, 2001: On the use of radar depolarization ratios for estimating shapes of ice hydrometeors in winter clouds. J. Appl. Meteor., 40, 479-490, https://doi.org/10.1175/15200450(2001)040<0479:OTUORD>2.0.CO;2.

Melnikov, V., and S. Matrosov, 2013: Radar measurements of the axis ratios of cloud particles. 36th Conf. on Radar Meteorology, Breckenridge, CO, Amer. Meteor. Soc., https:// ams.confex.com/ams/36Radar/webprogram/Manuscript/ Paper228291/AxisRatio.pdf.

, R. R. Lee, and N. J. Langlieb, 2012: Resonance effects within S-band in echoes from birds. IEEE Geosci. Remote Sens. Lett., 9, 413-416, https://doi.org/10.1109/LGRS.2011.2169933.

Nebuloni, R., C. Capsoni, and V. Vigorita, 2008: Quantifying bird migration by a high-resolution weather radar. IEEE Trans. Geosci. Remote Sens., 46, 1867-1875, https://doi.org/10.1109/ TGRS.2008.916467.

O'Bannon, T., 1995: Anomalous WSR-88D wind profilesMigrating bird? Preprints, 27th Conf. on Radar Meteorology, Vail, CO, Amer. Meteor. Soc., 663-664.
Steiner, M., and J. A. Smith, 2002: Use of three-dimensional reflectivity structure for automated detection and removal of nonprecipitating echoes in radar data. J. Atmos. Oceanic Technol., 19, 673-686, https://doi.org/10.1175/1520-0426(2002) 019<0673:UOTDRS $>2.0 . C O ; 2$.

Stepanian, P. M., K. G. Horton, V. M. Melnikov, D. S. Zrnić, and S. A. Gauthreaux Jr., 2016: Dual-polarization radar products for biological applications. Ecosphere, 7, e01539, https:// doi.org/10.1002/ecs2.1539.

Torvik, B., K. E. Olsen, and H. Griffiths, 2016: Classification of birds and UAVs based on radar polarimetry. IEEE Geosci. Remote Sens. Lett., 13, 1305-1309, https://doi.org/10.1109/ LGRS.2016.2582538.

van Gasteren, H., I. Holleman, W. Bouten, E. van Loon, and J. Shamoun-Baranes, 2008: Extracting bird migration information from C-band weather radar. Ibis, 150, 674-686, https://doi.org/10.1111/j.1474-919X.2008.00832.x.

Zawadzki, I., A. Bellon, C. Cote, and F. Fabry, 2001: Target identification by dual-polarization radar in operational environment. Preprints, 30th Conf. on Radar Meteorology, Munich, Germany, Amer. Meteor. Soc., 165-167.

Zhang, P., A. V. Ryzhkov, and D. S. Zrnić, 2004: Detection of birds and insects using polarimetric radar observation. 11th Conf. on Aviation, Range, and Aerospace Meteorology, 5, Hyannis, MA, Amer. Meteor. Soc., P5.13, https://ams.confex.com/ ams/11aram22sls/techprogram/paper_81616.htm.

Zrnić, D. S., and A. V. Ryzhkov, 1998: Observations of insects and birds with polarimetric radar. IEEE Trans. Geosci. Remote Sens., 36, 661-668, https://doi.org/10.1109/36.662746. 